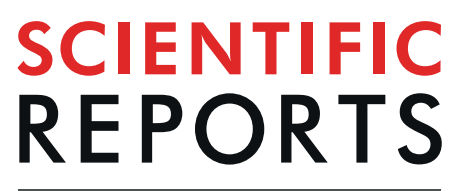

natureresearch

\title{
Significant enhancement of the bias stability of Zn-O-N thin-film transistors via Si doping
}

\begin{abstract}
Aeran Song ${ }^{1}$, Hyun-Woo Park ${ }^{1}$, Hyoung-Do Kim², Hyun-Suk Kim ${ }^{2 *}$ \& Kwun-Bum Chung ${ }^{\text {* }}$
Si doping was used to significantly improve the bias stability of ZnON thin-film transistors. Si 3W ( 1\%) doped ZnON TFTs showed a saturation mobility of $19.70 \mathrm{~cm}^{2} / \mathrm{Vs}$ along with remarkable improvements in the threshold voltage shift for negative gate bias stress (NBS) within $1.69 \mathrm{~V}$. The effects of Si doping were interpreted by the experimental correlation between device performance and physical analysis, as well as by the theoretical calculation. Si doping induces the reduction of $\mathrm{N}$-related defects by increasing stoichiometric $Z n_{3} N_{2}$, and decreasing nonstoichiometric $Z n_{x} N_{y}$. In addition, Si doping reduces the band edge states below the conduction band. According to density functional theory (DFT) calculations, $\mathrm{Si}$, when it substitutes for $\mathrm{Zn}$, acts as a carrier suppressor in the $\mathrm{ZnON}$ matrix.
\end{abstract}

Recently, zinc oxynitride ( $\mathrm{ZnON}$ ) thin-film transistors (TFTs) have attracted significant attention in next-generation, large size, and high-resolution display applications, because of their higher field-effect mobility ${ }^{1-9}$ than that of well-known amorphous indium-gallium-zinc oxide (a-IGZO) TFTs ${ }^{1,10,11}$. Previous studies on ZnON have shown that $\mathrm{ZnON}$-TFTs with high field effect mobility can be obtained using RF sputtering system with $\mathrm{Zn}$ metal target under a mixed reactive gas atmosphere (of $\mathrm{Ar}, \mathrm{O}_{2}$, and $\mathrm{N}_{2}$ ), which involves a simple and inexpensive process $^{2,3}$. Optimization of the $\mathrm{ZnON}$-TFT properties is normally performed by controlling the nitrogen $(\mathrm{N})$ to oxygen $(\mathrm{O})$ anion ratio $^{5,6}$, or thermal annealing ${ }^{7-9}$. As a result, the $\mathrm{ZnON}$-TFT obtains sufficiently low leakage current levels as well as high field effect mobility. It has been reported that the nitrogen vacant sites $\left(\mathrm{V}_{\mathrm{N}}\right)$ act as the major source of free electrons and carrier traps $s^{3,12-14}$ which may degrade the ZnON-TFT properties under bias stress. However, these previous studies have mainly focused on the field effect mobility on the device characteristics, and did not show enhanced bias stability. Therefore, the bias stability of the ZnON TFTs has yet to be fully clarified. Some previous studies have shown that the $\mathrm{Si}$ atoms could suppress oxygen deficiency ${ }^{15-17}$. Silicon oxide $(\mathrm{Si}-\mathrm{O}, 798 \mathrm{~kJ} / \mathrm{mol})^{18}$ has high oxygen bond dissociation energy and high chemical stability, so it can improve TFT stability. Also, silicon nitride $(\mathrm{Si}-\mathrm{N}, 439 \mathrm{~kJ} / \mathrm{mol})^{18}$ has higher bond dissociation energy than zinc nitride $(\mathrm{Zn}-\mathrm{N}, 160 \mathrm{~kJ} / \mathrm{mol})^{19}$ and high chemical stability, so the $\mathrm{N}$ can be kept in stable states in the films. Due to these advantages, Si was selected. However, previous studies have mostly focused on the device characteristics, and have not shown detailed electronic structure such as conduction band edge states below the conduction band using $\mathrm{x}$-ray absorption spectroscopy (XAS) and spectroscopic ellipsometry (SE) analysis and chemical bonding states such as Si peak using X-ray photoelectron spectroscopy (XPS) analysis. In this paper, we investigate the device performance of the $\mathrm{ZnON}$ and $\mathrm{Si}-\mathrm{ZnON} \mathrm{TFTs}$, and find, via electronic structure, chemical bonding states, and first-principle calculations analysis, that silicon ( $\mathrm{Si}$ ) doping during the thin film growth by co-sputtering a $\mathrm{SiO}_{2}$ target with $\mathrm{Zn}$ metal target can more effectively improve the bias stability of ZnON TFTs.

\section{Results and Discussion}

Figure 1(a) shows a schematic of the TFT structure of $\mathrm{ZnON}$ and Si-doped $\mathrm{ZnON}$. Figure 1(b) shows representative transfer characteristics of the TFTs with the Si-doped $\mathrm{ZnON}$ active layer deposited at $\mathrm{SiO}_{2}$ with $\mathrm{RF}$ powers of $(0$, 1,3 , and 5) W, which we indicate hereafter as $\mathrm{ZnON}, \mathrm{Si} 1 \mathrm{~W}-\mathrm{ZnON}, \mathrm{Si} 3 \mathrm{~W}-\mathrm{ZnON}$, and Si $5 \mathrm{~W}-\mathrm{ZnON}$, respectively. The field-effect mobility $\left(\mu_{\mathrm{FE}}\right)$ and threshold voltage $\left(\mathrm{V}_{\mathrm{th}}\right)$ in the saturation region $\left(\mathrm{V}_{\mathrm{DS}}=10 \mathrm{~V}\right)$ were calculated by fitting a straight line to the plot of the square root of $\mathrm{I}_{\mathrm{DS}}$ versus $\mathrm{V}_{\mathrm{GS}}{ }^{20}$. Table 1 shows the representative transfer parameters. As the Si doping power increased, the $\mu_{\mathrm{FE}}$ of the Si-doped ZnON TFTs gradually decreased from 114.35 to $11.37 \mathrm{~cm}^{2} / \mathrm{V}$ s for ZnON TFT to $\mathrm{Si} 5 \mathrm{~W}-\mathrm{ZnON}$ TFT. $\mathrm{Si}_{3} \mathrm{~N}_{4}$ is well-known to be electrically insulating ${ }^{21}$, so the decrease in $\mu_{\mathrm{FE}}$ is reasonable. Figure 1(c) shows representative output characteristics. As the Si doping power

${ }^{1}$ Division of Physics and Semiconductor Science, Dongguk University, Seoul, 04620, Republic of Korea. ${ }^{2}$ Department of Materials Science and Engineering, Chungnam National University, Daejeon, 34134, Republic of Korea. *email: khs3297@cnu.ac.kr; kbchung@dongguk.edu 

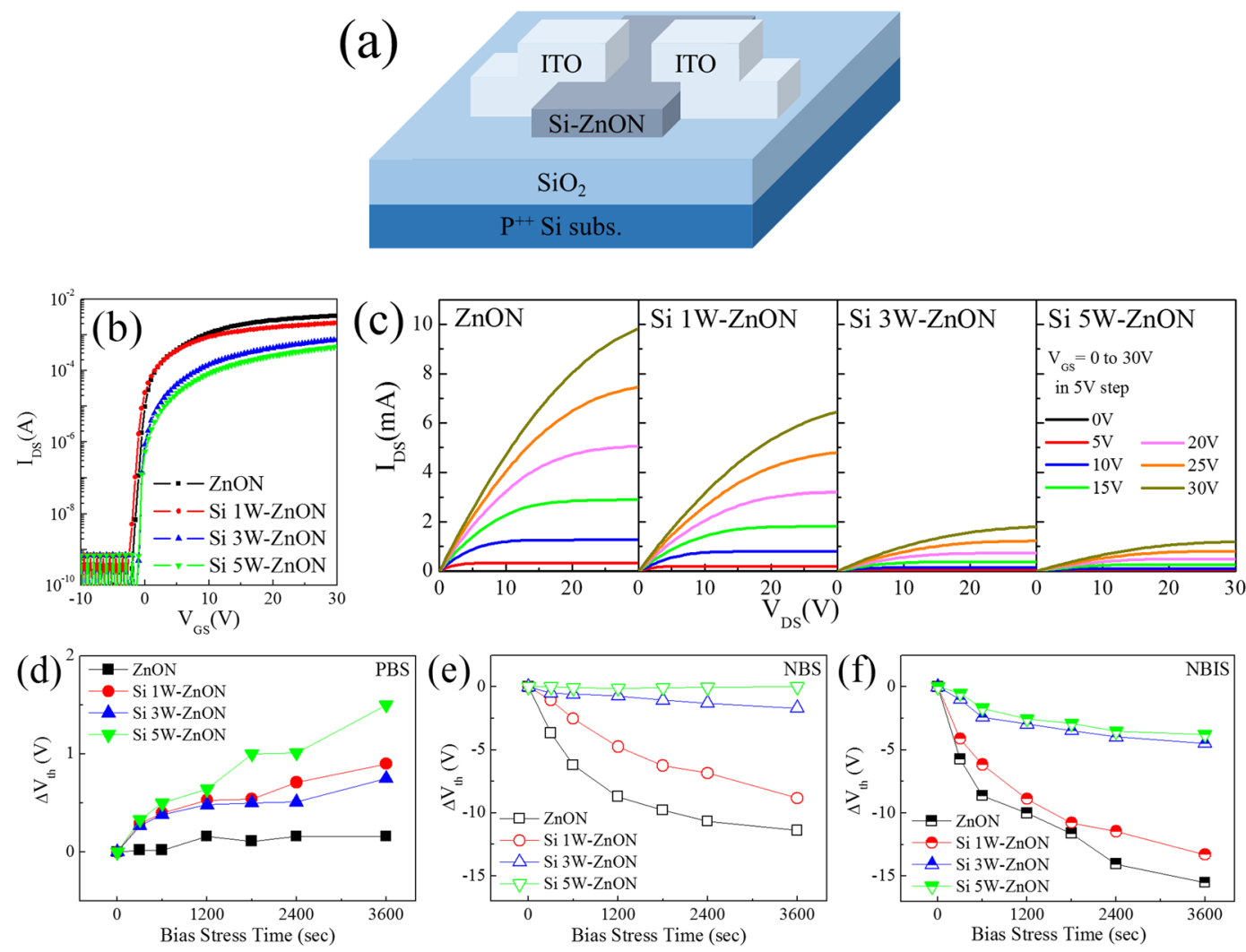

Figure 1. (a) Schematic of ZnON and Si-ZnON TFTs. (b) Transfer characteristics, and (c) output characteristics of the ZnON and Si-ZnON TFTs. The shift of threshold voltage under (d) PBS, (e) NBS, and (f) NBIS, of the ZnON and Si-ZnON TFTs.

\begin{tabular}{|l|l|l|l|l|}
\hline Sample & $\mathbf{V}_{\text {th }}[\mathbf{V}]$ & $\boldsymbol{\mu}_{\text {sat }}\left[\mathrm{cm}^{2} / \mathbf{V s}\right]$ & $\begin{array}{l}\text { S.S. }[\mathbf{V} / \\
\text { decade }]\end{array}$ & $\mathbf{I}_{\text {ON }} / \mathbf{I}_{\text {OFF }}$ \\
\hline ZnON & -1.09 & 114.35 & 0.37 & $3.38 \times 10^{7}$ \\
\hline Si 1W-ZnON & -1.56 & 94.95 & 0.38 & $2.12 \times 10^{7}$ \\
\hline Si 3W-ZnON & -0.51 & 19.70 & 0.20 & $7.32 \times 10^{6}$ \\
\hline Si 5 W-ZnON & -0.51 & 11.37 & 0.22 & $4.62 \times 10^{6}$ \\
\hline
\end{tabular}

Table 1. Representative transfer parameters of the $\mathrm{ZnON}$ and Si-doped $\mathrm{ZnON}$ TFTs.

increased, the output curves of the Si-doped ZnON TFTs gradually decreased. This output curve trend is similar to the transfer curve behavior. Figure $1(\mathrm{~d}, \mathrm{e})$ show the positive bias stress (PBS) and negative bias stress (NBS) tests with a positive gate bias of $20 \mathrm{~V}$ and negative gate bias $-20 \mathrm{~V}$ for $3,600 \mathrm{~s}$, respectively, that we performed in order to evaluate the effect of Si doping on the device bias stability. In addition, Fig. 1(f) shows the negative bias illumination stress (NBIS) tests with a negative gate bias of $-20 \mathrm{~V}$ and green light source with luminance of $1,500 \mathrm{~lx}$ for 3,600 s that we performed. Figure S1 of the Supplementary Information (SI) shows that as the stress time of positive gate bias increases, $\mathrm{ZnON}$ and Si-doped $\mathrm{ZnON}$ TFTs undergo positive shifts in threshold voltage $\left(\Delta \mathrm{V}_{\mathrm{th}}\right)$, without any significant degradations in device performance. The $\Delta \mathrm{V}_{\mathrm{th}}$ values under PBS are similar, but the $\Delta \mathrm{V}_{\text {th }}$ under NBS and NBIS of the ZnON TFT is larger than that of the Si-doped ZnON TFTs. The NBIS test results are similar to the NBS test results, in that as the Si doping power increased, the $\Delta V_{\text {th }}$ gradually decreases. Si doping improved the stability of NBS by about 7 times (before Si doping, $\Delta \mathrm{V}_{\text {th }}=-11.39 \mathrm{~V}$; after Si doping, $\Delta \mathrm{V}_{\mathrm{th}}=-1.69 \mathrm{~V}$ ). Si doping improved the stability of NBIS by about 4 times (before Si doping, $\Delta \mathrm{V}_{\text {th }}=-15.53 \mathrm{~V}$; after Si doping, $\Delta \mathrm{V}_{\mathrm{th}}=-3.78 \mathrm{~V}$ ). As a result, we confirmed that $\mathrm{Si}$ doping improved the device stability. Previous reports identified two main mechanisms for the shift in $\mathrm{V}_{\mathrm{th}}$. One of these is carrier trapping at the gate dielectric/ semiconductor interface ${ }^{22}$, while the other is the creation of additional defect states in the deep-gap states at, or near, the gate dielectric/semiconductor interface ${ }^{23}$. The charge trapping affected by the defect near the gate dielectric/semiconductor interface is considered to be the main degradation mechanism of the $\Delta V_{\text {th }}$, due to the subthreshold swing (SS) value not showing significant variations. The $\mathrm{V}_{\mathrm{N}}$ is ionized by holes that accumulate near the gate dielectric/semiconductor interface under NBS, and that release electrons ${ }^{24,25}$. The negative shift of $\mathrm{V}_{\text {th }}$ under NBS is related to the $V_{N}$ migration toward the gate dielectric/semiconductor interface ${ }^{26}$. The NBIS degradation mechanism is similar to that of the NBS degradation, except for the effect of the green light. Under NBIS, photon 

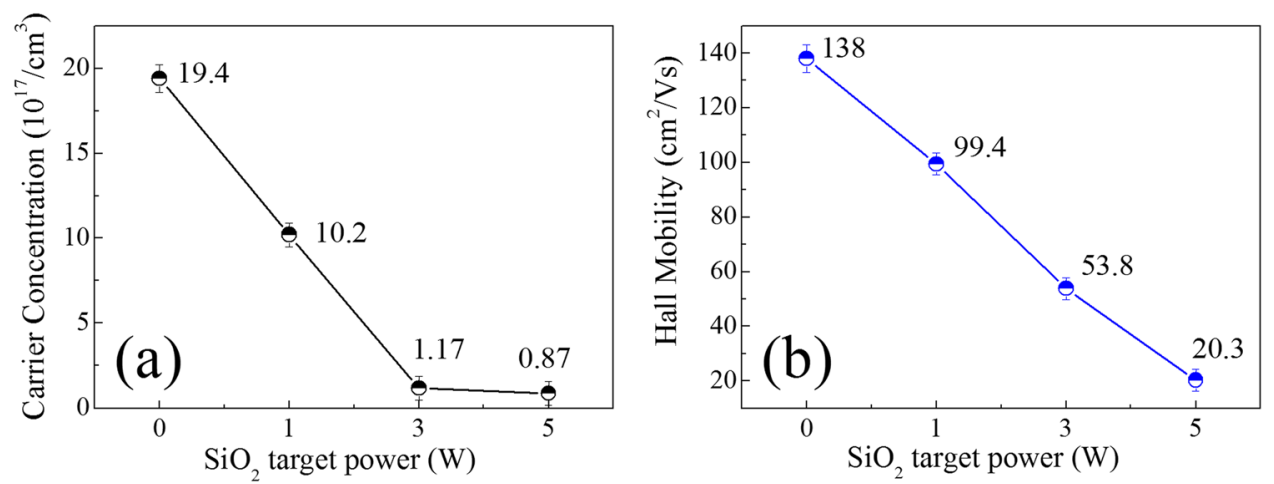

Figure 2. (a) Carrier concentration, and (b) Hall mobility, of the $\mathrm{ZnON}$ and Si-ZnON thin films.

\begin{tabular}{|l|l|l|l|l|l|}
\hline \multirow{4}{*}{ Sample } & C & N & O & Si & Zn \\
\cline { 2 - 6 } & \multicolumn{5}{|l|}{ Composition (\%) } \\
\hline ZnON & 5.3 & 4.2 & 42.3 & - & 48.2 \\
\hline Si 3W-ZnON & 5.5 & 2.3 & 43.8 & 0.9 & 47.5 \\
\hline
\end{tabular}

Table 2. Chemical compositions of $\mathrm{ZnON}$ and $\mathrm{Si} 3 \mathrm{~W}-\mathrm{ZnON}$ film as deduced from XPS peak areas.

radiation is likely to affect the ionization of $\mathrm{V}_{\mathrm{N}}$. Therefore, the negative $\mathrm{V}_{\text {th }}$ shift value under NBIS is larger, and appears earlier than under NBS. Meanwhile, the remarkable decrease in the $\Delta \mathrm{V}_{\text {th }}$ of the Si-ZnON TFTs under NBS and NBIS is related to the reduction of defects related to $V_{N}$, which may affect free electron generation. On the other hand, the positive shift of $\mathrm{V}_{\text {th }}$ under PBS was mostly due to the negative charge trapping in the semiconductor and/or gate dielectric/semiconductor interface ${ }^{27}$. However, the difference of negative charge trapping in the gate dielectric/semiconductor interface between $\mathrm{ZnON}$ and $\mathrm{Si}-\mathrm{ZnON}$ TFTs under PBS is negligible, and the changes of the positive $\Delta \mathrm{V}_{\mathrm{th}}$ did not show significant variations, compared with the changes of negative $\Delta \mathrm{V}_{\text {th }}$ under NBS. These results indicate that Si significantly suppresses the free electron generation under NBS, while it has very little effect on the negative charge trapping under PBS. The passivation of such defects by Si doping is suggested to improve the NBS stability of the device based on Si-doped $\mathrm{ZnON}$, as compared to that based on pure $\mathrm{ZnON}$.

Figure 2(a,b) show the carrier concentration and Hall mobility of $\mathrm{ZnON}$ and $\mathrm{Si}-\mathrm{ZnON}$ thin films, respectively, that were evaluated by Hall measurements. Si doping dramatically reduced the carrier concentration and Hall mobility values. This result is reasonable because $\mathrm{Si}_{3} \mathrm{~N}_{4}$ is well-known to be electrically insulating and these effects are similar to the tendency of decrease of the $\mu_{\mathrm{FE}}$. For further analyses, the Si $3 \mathrm{~W}-\mathrm{ZnON}$ film was selected as the optimum condition.

The Si doping concentrations, as well as changes in the chemical bonding states of $\mathrm{ZnON}$ and Si $3 \mathrm{~W}-\mathrm{ZnON}$ thin films, were examined through XPS analyses. The XPS spectra were measured after eliminating the surface contamination caused by adsorbed $\mathrm{OH}, \mathrm{C}, \mathrm{H}_{2} \mathrm{O}$, etc., and using $\mathrm{Ar}^{+}$ions at $500 \mathrm{eV}$, so as to minimize the preferred sputtering of light elements. Generally, all element spectra are calibrated by using the standard binding energy of carbon, which is of $284.5 \mathrm{eV}$. For this reason, we intentionally left the carbon. Based on previous studies ${ }^{20,28}$, Tables 2 and 3 summarize the estimated chemical composition and positions of the sub-peaks originating from specific bonds of the $\mathrm{ZnON}$ and $\mathrm{Si} 3 \mathrm{~W}-\mathrm{ZnON}$ layers, respectively. Figure 3(a) shows the O 1s spectra in XPS of the pure $\mathrm{ZnON}$ and $\mathrm{Si} 3 \mathrm{~W}-\mathrm{ZnON}$ films. The O 1s spectra were normalized and de-convoluted with three different Gaussian peaks, for detailed chemical bonding states of oxygen, which are located as low energy O1, middle energy $\mathrm{O} 2$, and high energy $\mathrm{O} 3$, respectively. The low binding energy (O1) to high binding energy (O3) peaks represent the metal-oxide (M-O) in $\mathrm{ZnO}$ lattices, the oxygen-deficient state within $\mathrm{ZnO}$ lattice, and the chemisorbed or dissociated oxygen states or $\mathrm{OH}$ - impurities, respectively ${ }^{20,29}$. Si doping slightly increased the relative areas of the $\mathrm{M}-\mathrm{O}$ bonding states $(\mathrm{O} 1)$, while it slightly decreased those of the oxygen-deficient bonding states $(\mathrm{O} 2)$. Si doping decreased the oxygen vacancies related to the $\mathrm{O} 2$, which contributed to the decrease in carrier concentration ${ }^{30}$. However this effect did not significantly affect the carrier concentration drop. Figure 3(b) shows the XPS N 1 s peak spectra of the pure $\mathrm{ZnON}$ and $\mathrm{Si} 3 \mathrm{~W}-\mathrm{ZnON}$ layers. The lowest energy sub-peak originates from $\mathrm{N}$ atoms in nonstoichiometric $\mathrm{Zn}_{\mathrm{x}} \mathrm{N}_{\mathrm{y}}\left(\right.$ Peak $\mathrm{A}$, including $\mathrm{V}_{\mathrm{N}}$ ), while peak $\mathrm{B}$ arises from the $\mathrm{N}$ atoms in stoichiometric $\mathrm{Zn}_{3} \mathrm{~N}_{2}$. The $\mathrm{C}$ and $\mathrm{C}^{\prime}$ peaks are $\mathrm{N}-\mathrm{N}$ and $\mathrm{SiN}_{\mathrm{x}}$ bonding states, respectively. The highest energy sub-peak represents mostly $\mathrm{N}_{2}$ or $\mathrm{NO}$ molecules states ${ }^{12,30,31}$. The important changes are the significant decreases of nonstoichiometric $\mathrm{Zn}_{\mathrm{x}} \mathrm{N}_{\mathrm{y}}$ and N-N bonds closely related to the carrier generation, and the increases of stoichiometric $\mathrm{Zn}_{3} \mathrm{~N}_{2}$ and $\mathrm{SiN}_{\mathrm{x}}$ bonds with $\mathrm{Si}$ doping. These results may be interpreted as being due to the passivation of vacant $\mathrm{N}$ sites by $\mathrm{Si}$ that contribute to the sub-peak originating from nonstoichiometric $\mathrm{Zn}_{\mathrm{x}} \mathrm{N}_{\mathrm{y}}$. Consequently, it can be seen that the carrier concentration drop is related to the decrease of nitrogen vacancy. Figure 3(c) shows the XPS Si 2 p peak spectra of the pure $\mathrm{ZnON}$ and $\mathrm{Si} 3 \mathrm{~W}-\mathrm{ZnON}$ layers. The three representatively assigned peaks 


\begin{tabular}{|l|l|l|l|l|l|}
\hline Index & Chemical states & $\begin{array}{l}\text { ZnON } \\
\text { Position }(\mathbf{e V})\end{array}$ & $\begin{array}{l}\mathrm{Si} \text { 3W-ZnON } \\
\text { Position }(\mathbf{e V})\end{array}$ & $\begin{array}{l}\mathrm{ZnON} \\
(\%)\end{array}$ & $\begin{array}{l}\text { Si 3W-ZnON } \\
(\%)\end{array}$ \\
\hline $\mathrm{O} 1$ & $\mathrm{Zn}-\mathrm{O}$ & 529.85 & 529.98 & 63.84 & 66.66 \\
\hline $\mathrm{O} 2$ & Oxygen deficient state & 530.70 & 530.80 & 22.04 & 19.68 \\
\hline $\mathrm{O} 3$ & $\mathrm{CO}, \mathrm{OH}$ etc & 531.88 & 531.88 & 14.13 & 13.66 \\
\hline $\mathrm{A}$ & Defective $\mathrm{Zn}_{\mathrm{x}} \mathrm{N}_{\mathrm{y}}$ & 395.50 & 395.50 & 33.46 & 15.85 \\
\hline $\mathrm{B}$ & Stoichiometric $\mathrm{Zn}_{3} \mathrm{~N}_{2}$ bond & 396.40 & 396.40 & 44.23 & 46.29 \\
\hline $\mathrm{C}$ & $\mathrm{N}-\mathrm{N}$ bond & 397.60 & 397.60 & 15.06 & 4.21 \\
\hline $\mathrm{C}^{\prime}$ & $\mathrm{SiN}_{\mathrm{x}}$ bond & - & 397.90 & - & 28.06 \\
\hline $\mathrm{D}$ & $\mathrm{NO}_{2}$ bond & 403.60 & 403.50 & 7.25 & 5.59 \\
\hline $\mathrm{E}$ & $\mathrm{Si}^{2+} / \mathrm{SiN}_{\mathrm{x}}$ bond & - & 101.00 & - & 14.63 \\
\hline $\mathrm{F}$ & $\mathrm{SiN}_{\mathrm{x}}$ bond & - & 101.66 & - & 67.52 \\
\hline $\mathrm{G}$ & $\mathrm{SiN}_{1.33} / \mathrm{SiO}_{\mathrm{x}}$ bond & - & 102.27 & - & 17.86 \\
\hline
\end{tabular}

Table 3. Summary of XPS peak position with assignment of featured sub-peaks for the O 1 s, N 1 s, and Si 2p spectra.
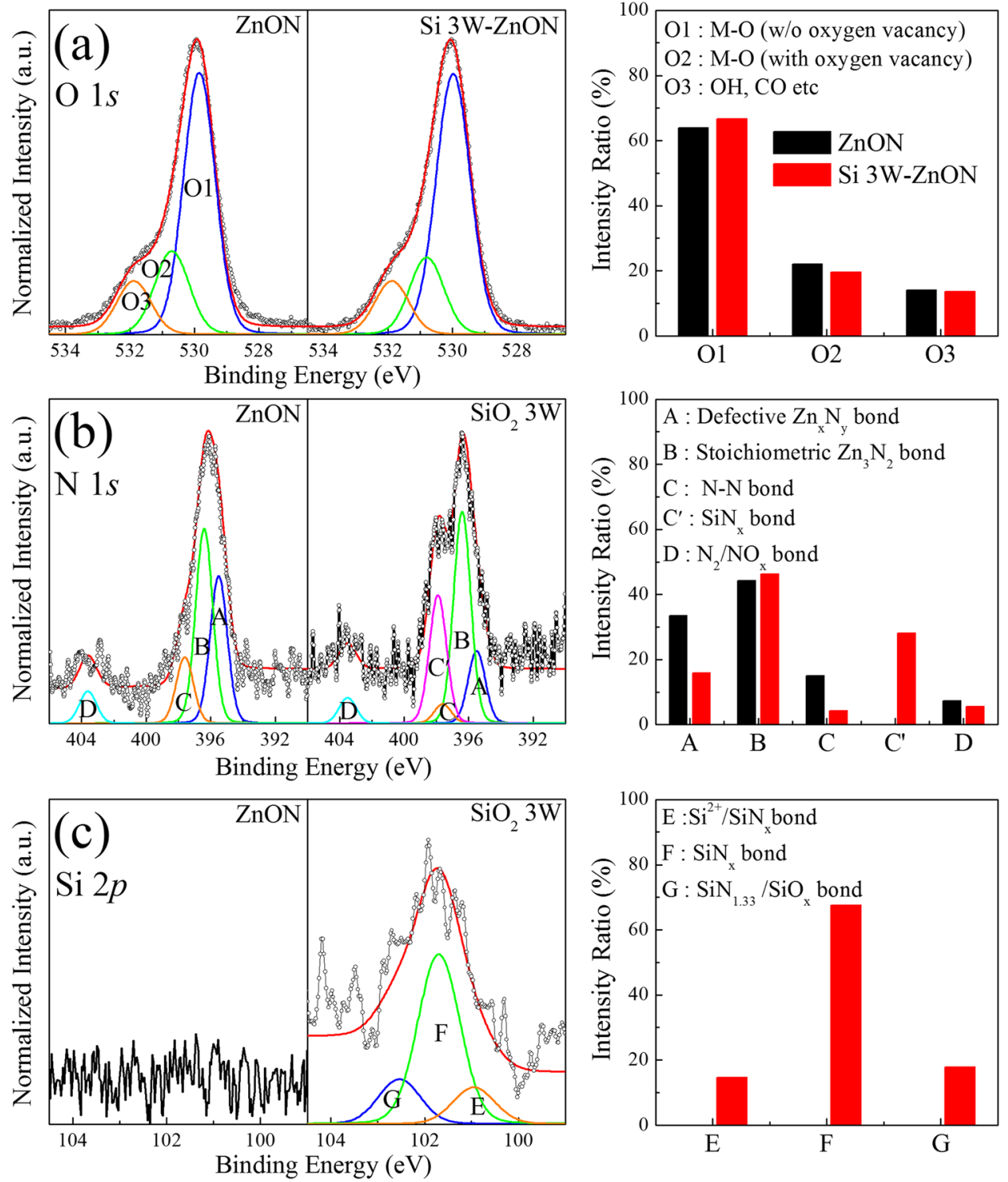

Figure 3. Deconvoluted XPS (a) O 1s, (b) N 1s, and (c) Si 2p spectra and relative intensity ratio, of the ZnON and $\mathrm{Si} 3 \mathrm{~W}-\mathrm{ZnON}$ thin films. 


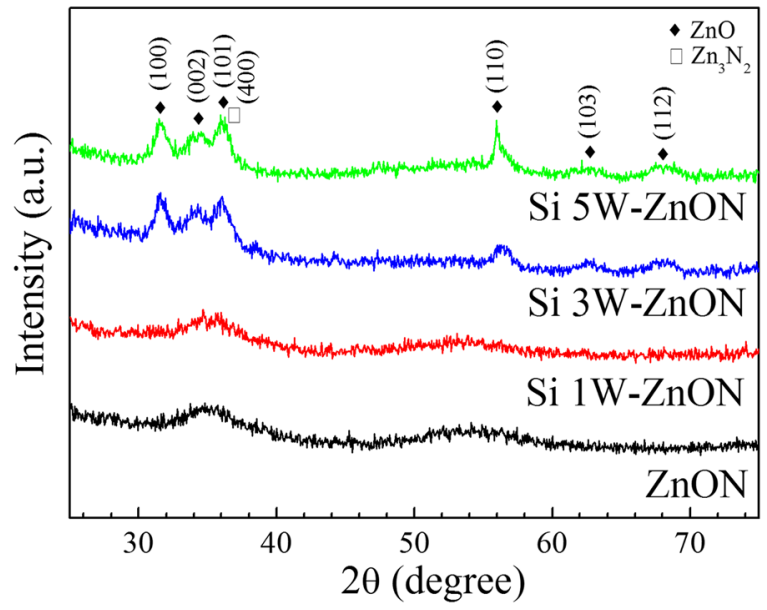

Figure 4. Grazing incidence angle $\mathrm{x}$-ray diffraction patterns of the $\mathrm{ZnON}$ and Si-doped $\mathrm{ZnON}$ films.

from low binding energy are related to the $\mathrm{Si}^{2+}$, nonstoichiometric $\mathrm{SiN}_{\mathrm{x}}$, and the $\mathrm{SiN}_{1.33}$ or $\mathrm{SiO}_{\mathrm{x}}$ bonding states, respectively ${ }^{30,32,33}$.

In order to consider the physical structure of the $\mathrm{ZnON}$ and $\mathrm{Si}$-doped $\mathrm{ZnON}$ thin films, we measured grazing incident angle $\mathrm{x}$-ray diffraction (GIAXRD, Rigaku). Figure 4 shows the XRD patterns of the ZnON and Si-doped $\mathrm{ZnON}$ thin films that were obtained from $25^{\circ}$ to $75^{\circ}$ by using the fixed incident beam angle $\left(\omega, 1^{\circ}\right)$ during $2 \theta$. The XRD patterns of the $\mathrm{ZnON}$ and $\mathrm{Si} 1 \mathrm{~W}-\mathrm{ZnON}$ thin films exhibit amorphous structures; whereas, the Si $3 \mathrm{~W}$ and $\mathrm{Si}$ $5 \mathrm{~W}-\mathrm{ZnON}$ thin films exhibit six peaks, which correspond to the (100), (002), (101), (110), (103), and (112) peaks of hexagonal $\mathrm{ZnO}$, and the peak positions overlap with the (400) peak of cubic $\mathrm{Zn}_{3} \mathrm{~N}_{2}^{2,34}$. These results are correlated to the increase of the $\mathrm{ZnO}$ bond and the stoichiometric $\mathrm{Zn}_{3} \mathrm{~N}_{2}$ bond in Si $3 \mathrm{~W}-\mathrm{ZnON}$ film by XPS, as shown in Fig. 3. We believe that the four phases of $\mathrm{Zn}_{3} \mathrm{~N}_{2}, \mathrm{ZnO}$, amorphous $\mathrm{ZnON}$ (a- $\mathrm{ZnON}$ ) and nano-crystallites $\mathrm{ZnON}$ (nc-ZnON) co-exist in Si $3 \mathrm{~W}$ and Si $5 \mathrm{~W}-\mathrm{ZnON}$ thin films. In order to elucidate the improvement of the device stability of the $\mathrm{Si} 3 \mathrm{~W}$-ZnON TFTs in terms of the electronic structures, we evaluated the conduction band and band edge state of the $\mathrm{ZnON}$ and $\mathrm{Si} 3 \mathrm{~W}-\mathrm{ZnON}$ films.

Figure 5(a) shows the XAS spectra of the normalized O K-edge, which provides more information over a wider conduction band, as well as the unoccupied hybridized states of the $\mathrm{ZnON}$ and $\mathrm{Si} 3 \mathrm{~W}-\mathrm{ZnON}$ films. The O K-edge spectra were obtained by deducting the $\mathrm{x}$-ray background and scaling the post-edge levels to a uniform value. Following normalization, the relative intensity can explain the transition of an electron from the $\mathrm{O} 1 \mathrm{~s}$ orbital to the unoccupied zinc $4 \mathrm{~s}$ and $4 \mathrm{sp}$ molecular orbitals of $\mathrm{ZnON}$ based on symmetrically determined models, and the energy levels of the molecular orbital states can be obtained by the second derivative of the O K-edge spectra $^{35}$. The band edge states $\mathrm{D}_{1}$ below the conduction band edge were detected from the second-derivative spectra. For further detailed analysis of the band edge states below the conduction band, Gaussian fits were performed. Figure 5(b) shows XAS O K-edge spectra over a narrow energy region below the conduction band for $\mathrm{ZnON}$ and Si $3 \mathrm{~W}-\mathrm{ZnON}$ films. The band edge states $\mathrm{D}_{1}$ of $\mathrm{ZnON}$ and $\mathrm{Si} 3 \mathrm{~W}-\mathrm{ZnON}$ films are $532.1 \mathrm{eV}$, and the conduction band positions of $\mathrm{ZnON}$ and $\mathrm{Si} 3 \mathrm{~W}-\mathrm{ZnON}$ films are $532.2 \mathrm{eV}$ and $532.28 \mathrm{eV}$, respectively. The defect states $\mathrm{D}_{1}$ are close to the conduction band edge, which is located about 0.1 to $0.2 \mathrm{eV}$ (for $\mathrm{ZnON}$ to Si $3 \mathrm{~W}-\mathrm{ZnON}$, respectively) below the conduction band. The relative areas of $\mathrm{D}_{1}$ slightly decreased with $\mathrm{Si}$ doping. Previous studies on metal oxides have indicated some correlation between band-edge states and electrical properties such as carrier concentration and mobility ${ }^{36,37}$. Generally, the defect states below the conduction band edge might be divided into two states. One is the shallow band edge states close to the conduction band edge $\mathrm{e}^{38}$. This relative defect state reduction below the conduction band edge is related to the decrease of the free electron by the generation of oxygen vacancies. The other is the deep band edge state far from the conduction band ${ }^{39}$. The degradation of carrier mobility is related to the deep band edge states, which are unoccupied states. In this state, the charge trapping and charge scattering are increased under carrier transport due to energy levels. In this paper, we obtained the defect states $\left(D_{1}\right)$ close to the conduction band edge, which is located about 0.1 to $0.2 \mathrm{eV}$ (for $\mathrm{ZnON}$ to $\mathrm{Si}$ $3 \mathrm{~W}-\mathrm{ZnON}$, respectively), below the conduction band. This defect state $\mathrm{D}_{1}$ is similar to the shallow band edge state type shown in some previous reports. Therefore, it seems that the reduction of the relative defect state is related to the decrease of the carrier concentration by Si doping. This tendency is similar to the decrease of oxygen vacancy (O2) in Fig. 3(a). However, it seems that these results will not have that much impact on the decrease of carrier concentration. The decrease of carrier concentration seems likely to be strongly influenced by the reduction of the $\mathrm{Zn}_{\mathrm{x}} \mathrm{N}_{\mathrm{y}}$ and $\mathrm{N}-\mathrm{N}$ bond related to the $\mathrm{V}_{\mathrm{N}}$, as shown in Fig. 3, rather than the decrease of oxygen vacancy.

Figure 6(a) shows the imaginary parts of the dielectric function $\left(\varepsilon_{2}\right)$ spectra that were obtained by spectroscopic ellipsometry (SE) using rotating analyser system with the incident angles of $65^{\circ}, 70^{\circ}$, and $75^{\circ}$ in the energy range 1 to $5 \mathrm{eV}$. These spectra were extracted from a simple four-phase model comprising a Si substrate, thermal $\mathrm{SiO}_{2}$ layer, $\mathrm{ZnON}$ layer, and an ambient layer. Further detailed and quantitative analysis of the band edge states and unoccupied trap states within the forbidden gap was performed using Gaussian function fitting ${ }^{40}$. The band gap of the Si $3 \mathrm{~W}-\mathrm{ZnON}$ films lies upward of $\sim 0.1 \mathrm{eV}$ relative to $\mathrm{ZnON}$. Figure $6(\mathrm{~b})$ shows the enlargement of 

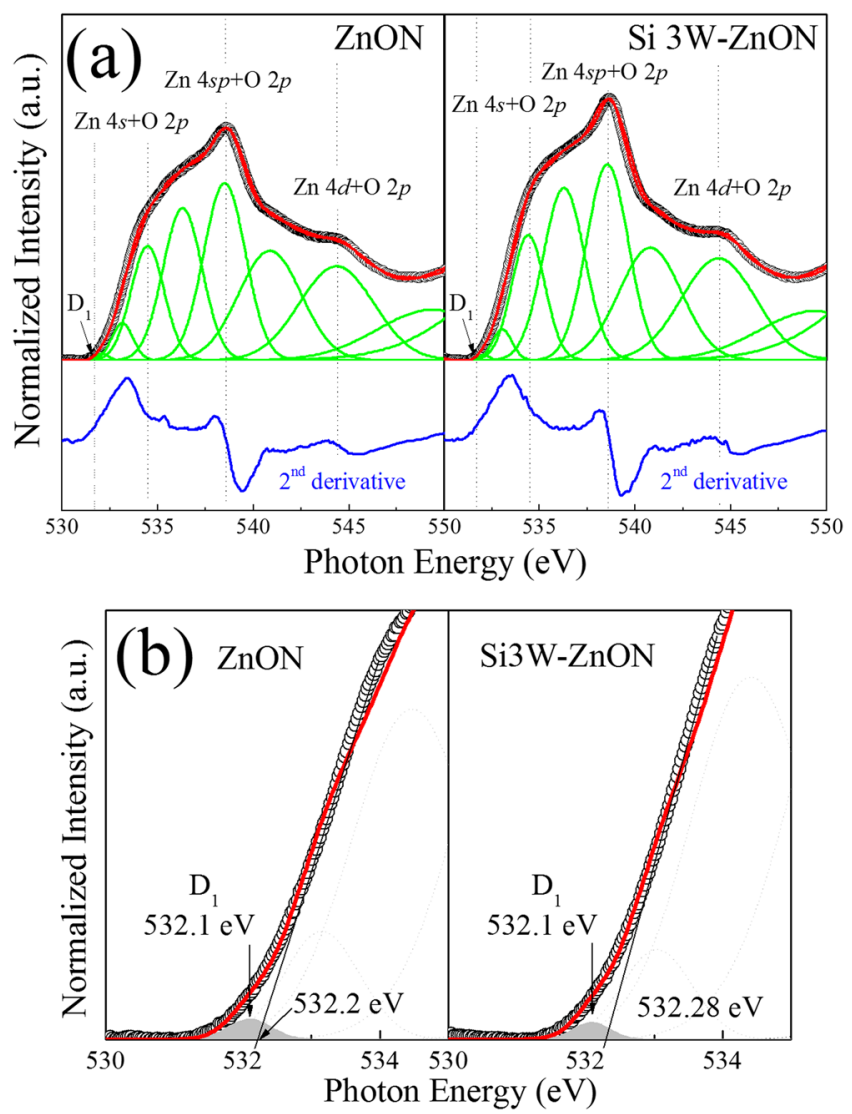

Figure 5. (a) Deconvoluted O K-edge XAS spectra, and (b) enlargement of the XAS spectra for band edge states below the conduction band, of the $\mathrm{ZnON}$ and $\mathrm{Si} 3 \mathrm{~W}-\mathrm{ZnON}$ thin films.
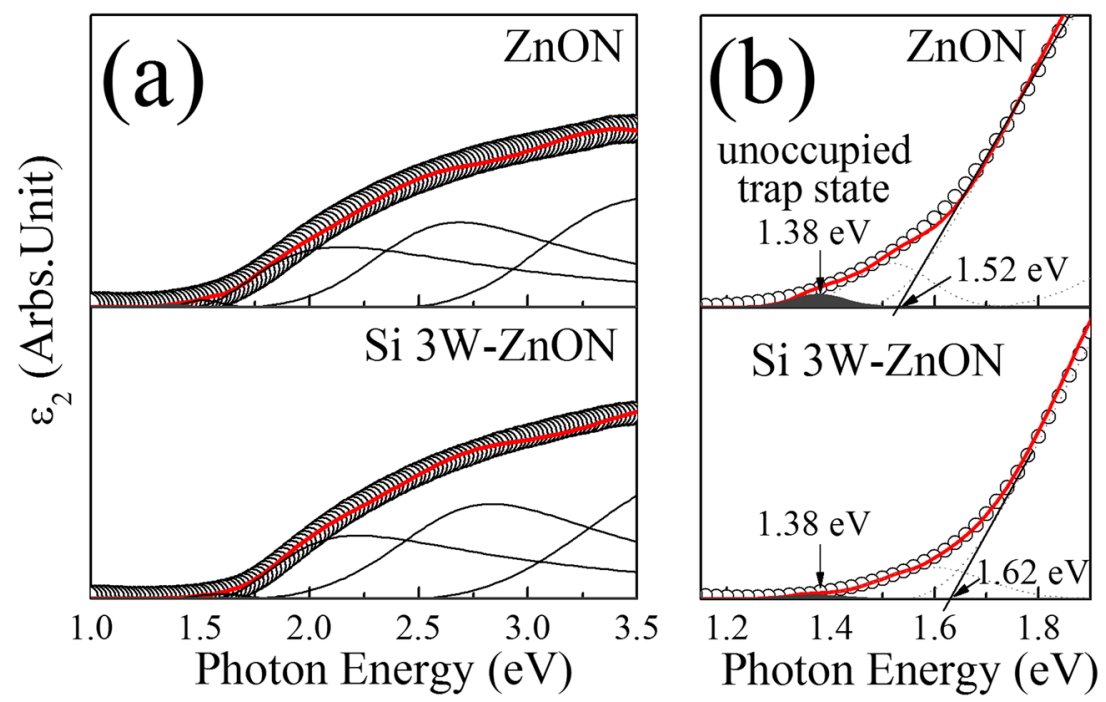

Figure 6. (a) Imaginary part of the dielectric function $(\varepsilon 2)$ spectra, and (b) enlargements of the $\varepsilon 2$ spectra below the conduction band, of the $\mathrm{ZnON}$ and $\mathrm{Si} 3 \mathrm{~W}-\mathrm{ZnON}$ thin films.

the $\varepsilon_{2}$ spectra for the band edge states below the conduction band, which represents the unoccupied trap state within the forbidden gap for the $\mathrm{ZnON}$ and $\mathrm{Si} 3 \mathrm{~W}-\mathrm{ZnON}$ films. The unoccupied trap state position lies close to the conduction band edge, which is located about 0.14 to $0.24 \mathrm{eV}$ ( $\mathrm{ZnON}$ to Si $3 \mathrm{~W}-\mathrm{ZnON}$, respectively) below the conduction band. Si doping decreased the relative band edge state area, which results are consistent with those of previous XAS analyses.

In order to study the effects of $\mathrm{Si}$ doping in $\mathrm{ZnON}$, MD simulations were performed to obtain amorphous $\mathrm{ZnON}$ supercells, and DFT calculations were adopted to generate the atomic structures of $\mathrm{ZnON}$ containing 


\begin{tabular}{|l|l|l|l|l|}
\hline \multirow{2}{*}{ Structure } & N & O & Si & Zn \\
\cline { 2 - 5 } & Atomic ratio (\%) \\
\hline ZnON & 4.5 & 44.4 & 0 & 51.1 \\
\hline Si 3W-ZnON & 2.3 & 47.8 & 1.1 & 48.8 \\
\hline
\end{tabular}

Table 4. Atomic ratio of simulated $\mathrm{ZnON}$ and $\mathrm{Si} 3 \mathrm{~W}-\mathrm{ZnON}$ structures.

(a)

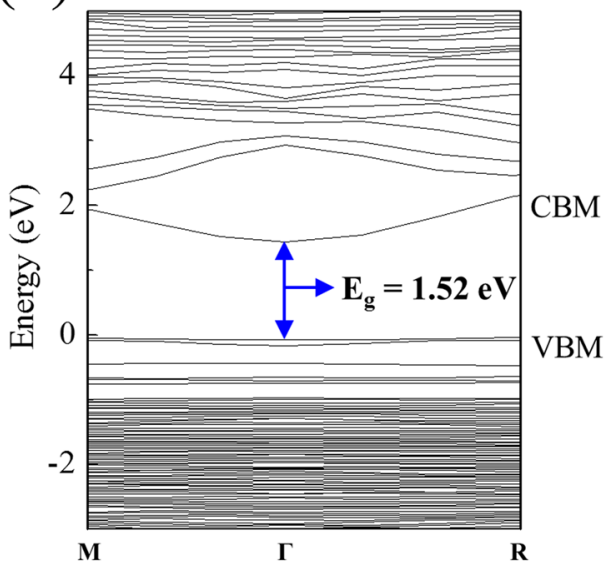

(b)

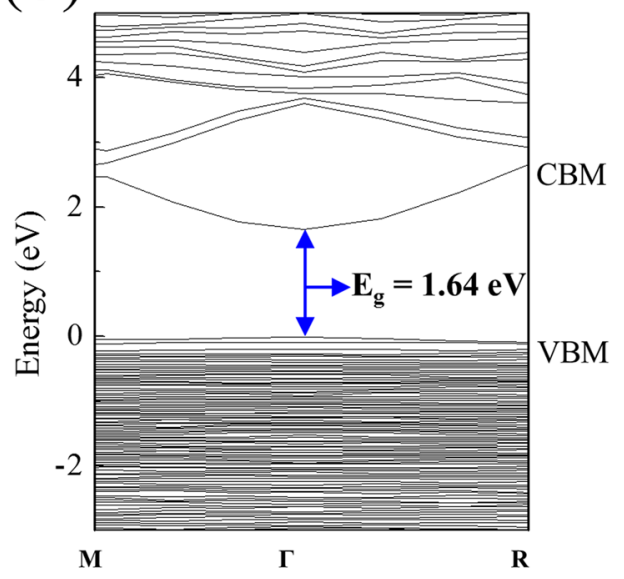

(c)

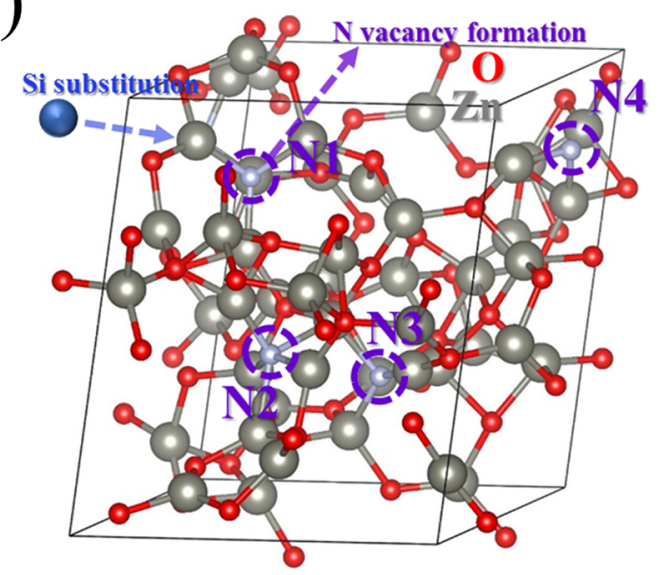

Figure 7. Calculated band structures of (a) $\mathrm{ZnON}$, and (b) Si $3 \mathrm{~W}-\mathrm{ZnON}$; and (c) schematic of the Si-doped $\mathrm{ZnON}$.

doped Si and various vacancies. Table 4 and Fig. 7(a,b) show the elemental ratio of amorphous $\mathrm{ZnON}$ and $\mathrm{Si}$ $3 \mathrm{~W}-\mathrm{ZnON}$ structures, and the calculated band gap energy of amorphous $\mathrm{ZnON}$ and $\mathrm{Si} 3 \mathrm{~W}-\mathrm{ZnON}$ by $\mathrm{MD}$ simulations, respectively, where the ratio and band gap energy were almost the same as the experimental data (Table 2 and Fig. 6(b)). Figure 7(c) shows $\mathrm{N}$ atoms in amorphous ZnON, which are labelled from N1 to N4, and Si substitution for $\mathrm{Zn}$ was carried out. The vacancy formation energies in $\mathrm{ZnON}$ and $\mathrm{Si} 3 \mathrm{~W}-\mathrm{ZnON}, \mathrm{E}_{\text {form }}$ are calculated as follows:

$$
\mathrm{E}_{\text {form }}=\mathrm{E}(\text { vacancy })-\mathrm{E}(\text { pure })+\mu_{\text {element }}
$$

where $\mathrm{E}$ (vacancy) is the energy of $\mathrm{ZnON}$ or $\mathrm{Si} 3 \mathrm{~W}-\mathrm{ZnON}$ with certain vacancy such as $\mathrm{N}, \mathrm{O}, \mathrm{Si}$, and $\mathrm{Zn}$, while $\mathrm{E}$ (pure) corresponds to the energy of $\mathrm{ZnON}$ or $\mathrm{Si} 3 \mathrm{~W}-\mathrm{ZnON}$ without any vacancy. $\mu_{\text {element }}$ represents the chemical potential of elements, which was calculated by the energy of cation or the half energy of anion molecule ${ }^{41}$. $\mathrm{E}_{\text {form }}\left(\mathrm{V}_{\mathrm{N}}\right)$ was calculated by removing each $\mathrm{N}$ atom site $(\mathrm{N} 1-\mathrm{N} 4)$ in $\mathrm{ZnON}$ or Si $3 \mathrm{~W}-\mathrm{ZnON}$. Similarly, the O, $\mathrm{Zn}$ and $\mathrm{Si}$ vacancies were calculated by removing each atom.

Table 5 shows the vacancy formation energies of each atom site in $\mathrm{ZnON}$ and $\mathrm{Si} 3 \mathrm{~W}-\mathrm{ZnON}$ structures. The calculation results indicate that the formation energies of $\mathrm{N}$ vacancies $\left(\mathrm{V}_{\mathrm{N}}\right)$ in the pure amorphous $\mathrm{ZnON}$ matrix were negative, or were almost zero values $\left(\mathrm{E}_{\mathrm{form}}=-0.312 \pm 0.255 \mathrm{eV}\right)$, which means that $\mathrm{V}_{\mathrm{N}} \mathrm{s}$ are easily formed 


\begin{tabular}{|l|l|l|l|l|l|l|l|l|}
\hline \multirow{3}{*}{ Type } & \multicolumn{9}{|l|}{ ZnON } & Si 3W-ZnON \\
\cline { 2 - 9 } & Site 1 & Site 2 & Site 3 & Site 4 & Site 1 & Site 2 & Site 3 & Site 4 \\
\cline { 2 - 9 } & Formation energies (eV) \\
\hline $\mathrm{V}_{\mathrm{N}}$ & -0.567 & -0.188 & 0.057 & -0.442 & 2.318 & 1.549 & 0.714 & 1.581 \\
\hline $\mathrm{V}_{\mathrm{O}}$ & 3.079 & 3.446 & 3.093 & 3.027 & 4.788 & 4.952 & 4.506 & 4.491 \\
\hline $\mathrm{V}_{\mathrm{Zn}}$ & 2.879 & 3.414 & 3.093 & 3.250 & N/A & N/A & N/A & N/A \\
\hline $\mathrm{V}_{\mathrm{Si}}$ & N/A & N/A & N/A & N/A & 6.049 & 5.552 & 3.801 & 5.866 \\
\hline
\end{tabular}

Table 5. Vacancy formation energies of each $\mathrm{N}$ site in $\mathrm{ZnON}$ and $\mathrm{Si} 3 \mathrm{~W}-\mathrm{ZnON}$ structures.

and could act as defect states. However, when Si substitutes for $\mathrm{Zn}$ near each $\mathrm{N}$ atom, the formation energies are significantly increased $\left(\mathrm{E}_{\text {form }}=1.516 \pm 0.802 \mathrm{eV}\right)$ from pure $\mathrm{ZnON}$. Moreover, the formation energy of $\mathrm{O}$ vacancy $\left(\mathrm{V}_{\mathrm{O}}\right)$ is increased for the $\mathrm{O}$ near substituted $\mathrm{Si}$, and the substituted $\mathrm{Si}$ had much higher vacancy formation energy than $\mathrm{Zn}$ vacancies $\left(\mathrm{V}_{\mathrm{Zn}}\right)$. These results are consistent with the experimental data, i.e. the suppression of anion vacancy formation by Si doping in amorphous $\mathrm{ZnON}$.

Figure $8(a, b)$ show schematics of the degradation mechanism under NBS with band bending states on the gate dielectric/channel interface of ZnON and Si 3W-ZnON TFTs, respectively. Figure 8(c,d) show the degradation mechanism of $\mathrm{ZnON}$ and $\mathrm{Si} 3 \mathrm{~W}-\mathrm{ZnON}$ TFTs respectively, under NBIS. These band bending states under NBS and NBIS will be partially occupied by $\mathrm{V}_{\mathrm{N}}{ }^{3+}$, and cause the Fermi energy $\left(\mathrm{E}_{\mathrm{F}}\right)$ level to shift by higher than half value of the band gap by n-type semiconductor characteristics. As a result, these are usually electron donor states, as they will tend to increase electron occupation of the conduction band. Meanwhile, these states are closely associated with degradation of the device stability.

To be more specific, when a negative bias is applied at the gate of the ZnON TFT, the $\mathrm{E}_{\mathrm{F}}$ shifts towards the middle of the band gap, and $\mathrm{V}_{\mathrm{N}}{ }^{3+}$ migrates more closely toward the gate dielectric/channel interface. Furthermore, the amount of electron and electron trap sites increases, due to the released electrons from the weakly bonded unstable defect states $\left(\mathrm{V}_{\mathrm{N}}\right.$ related to $\mathrm{ZnO}_{\mathrm{x}} \mathrm{N}_{\mathrm{y}}$, and/or $\left.\mathrm{Zn}_{\mathrm{x}} \mathrm{N}_{\mathrm{y}}\right)$, thereby deteriorating the stability of the device as shown in Fig. 8(a,b). In the case of NBIS, the greater amount of $\mathrm{V}_{\mathrm{N}}{ }^{3+}$ accumulated at the gate dielectric/channel interface will increase by photon radiation, as shown in Fig. 8(c,d). However, in the case of Si 3W-ZnON TFT, the unstable $\mathrm{N}$ defect states and released electrons were decreased, due to the Si likely suppressing the $\mathrm{V}_{\mathrm{N}}$ sites. Considering the previous electrical data of device bias stability, chemical bonding states, band edge states below the conduction band, and DFT simulations shown respectively from Figs 1-7, device instability is strongly correlated with $\mathrm{V}_{\mathrm{N}}$, and $\mathrm{Si}$ doping could be the plausible origin of the enhanced device bias instability. Si doping decreased the $\mathrm{V}_{\mathrm{N}}$ defects, which can enhance the device bias stability in $\mathrm{Si} 3 \mathrm{~W}-\mathrm{ZnON}$ by suppressing free electron generation.

\section{Conclusion}

In conclusion, we evaluated the electrical properties of Si-doped $\mathrm{ZnON}$ thin film transistor and interpreted their origins using experimental analysis and theoretical calculation. Si $3 \mathrm{~W}(\sim 1 \%)$-doped ZnON TFTs showed a saturation mobility of $19.70 \mathrm{~cm}^{2} / \mathrm{Vs}$ as well as dramatic improvements in the threshold voltage shift for NBS within 1.69 V. Doped Si substitutes for zinc sites and induces increases in stoichiometric $\mathrm{Zn}_{3} \mathrm{~N}_{2}$ bonds and decreases in defective $\mathrm{Zn}_{\mathrm{x}} \mathrm{N}_{\mathrm{y}}$ bonds. DFT calculations also suggest that $\mathrm{Si}$ is likely to suppress $\mathrm{V}_{\mathrm{N}}$ formation. Therefore, the improvement of bias stability in Si-doped $\mathrm{ZnON}$ TFT originates from the strong suppression of $\mathrm{V}_{\mathrm{N}} \mathrm{s}$, and the small number of electron-trap sites.

\section{Methods}

Fabrication of the Si-ZnON TFTs. First, 40nm-thick $\mathrm{ZnON}$ and Si-doped $\mathrm{ZnON}$ layers were grown on highly doped $p$-type $\mathrm{Si}$ substrates with a thermally grown $100 \mathrm{~nm}$-thick $\mathrm{SiO}_{2}$ dielectric layer by co-sputtering $\mathrm{Zn}$ and $\mathrm{SiO}_{2}$ targets. The power exerted on the $\mathrm{Zn}$ metal target and on the $\mathrm{SiO}_{2}$ target was fixed at DC $100 \mathrm{~W}$ and varied, respectively. The reactive gas flow rate ratio was $\mathrm{Ar}: \mathrm{O}_{2}: \mathrm{N}_{2}=3: 3.4: 40$ and the chamber pressure was 5 mTorr. Then, an indium tin oxide source/drain electrode was deposited and patterned using shadow masks. The fabricated TFTs had a bottom gate structure as well as a channel width (W) and length (L) of 800 and $200 \mu \mathrm{m}$, respectively. Finally, the $\mathrm{ZnON}$ and $\mathrm{Si}$-doped $\mathrm{ZnON}$ TFTs were annealed at $300^{\circ} \mathrm{C}$ for $1 \mathrm{~h}$ in air atmosphere, using a furnace system. The transfer characteristics and bias stability of the ZnON TFTs with respect to the Si doping power were measured at room temperature (RT), using a semiconductor parameter analyzer.

Electrical and physical measurements. The transfer characteristics, output characteristics, and gate bias stability behaviors of the ZnON TFT and Si-ZnON TFT devices were measured at RT using the Keithley SCS-4200 semiconductor-parameter analyzer. The electrical properties, such as carrier concentration and Hall mobility, of $\mathrm{ZnON}$ and Si-ZnON thin films were measured at RT using the Hall measurement system with 0.56-Tesla permanent magnet. During the electrical measurements, the drain-to-source voltage $\left(V_{D S}\right)$ was fixed at $10 \mathrm{~V}$, and the drain-to-source current $\left(I_{D S}\right)$ was measured in gate-to-source voltage $\left(V_{G S}\right)$ from -30 to $30 \mathrm{~V}$. GIAXRD with incident beam angle $1^{\circ}$, was performed in order to obtain the physical structure of the $\mathrm{ZnON}$ and Si-doped $\mathrm{ZnON}$ thin films, using $\mathrm{Cu} \mathrm{K} \alpha$ radiation (Rigaku).

Electronic-structure measurements. The changes of the chemical bonding states depending on the $\mathrm{Si}$ doping were examined by XPS using a monochromatic $\mathrm{Al} \mathrm{K \alpha}$ source with a pass energy of $29.35 \mathrm{eV}$. In addition, the electronic structure and band edge states below the conduction band of the Si-doped $\mathrm{ZnON}$ films were 
(a) NBS

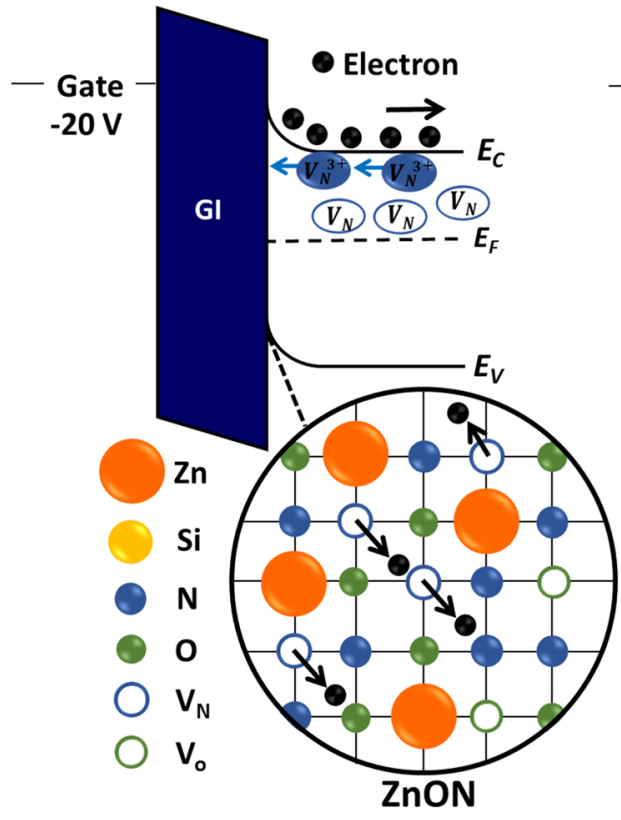

(c) NBIS

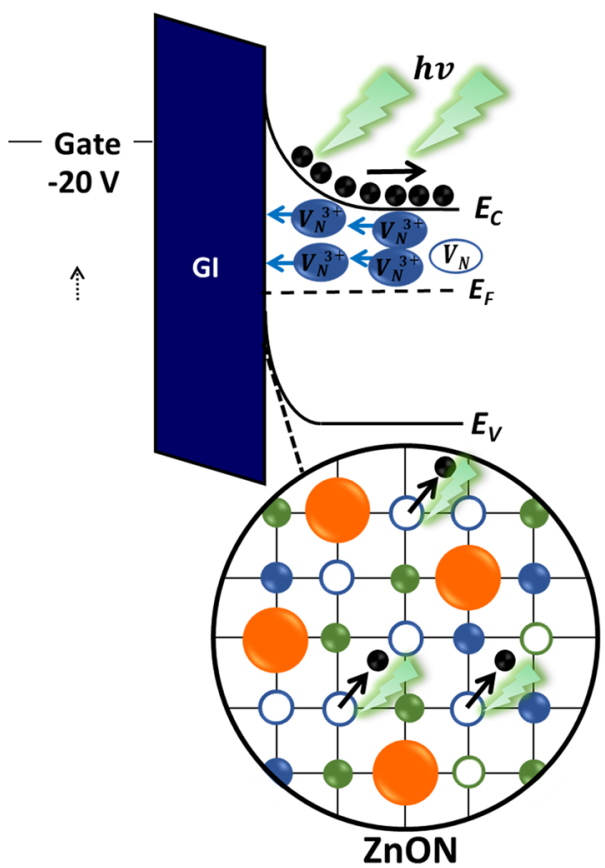

(b) NBS

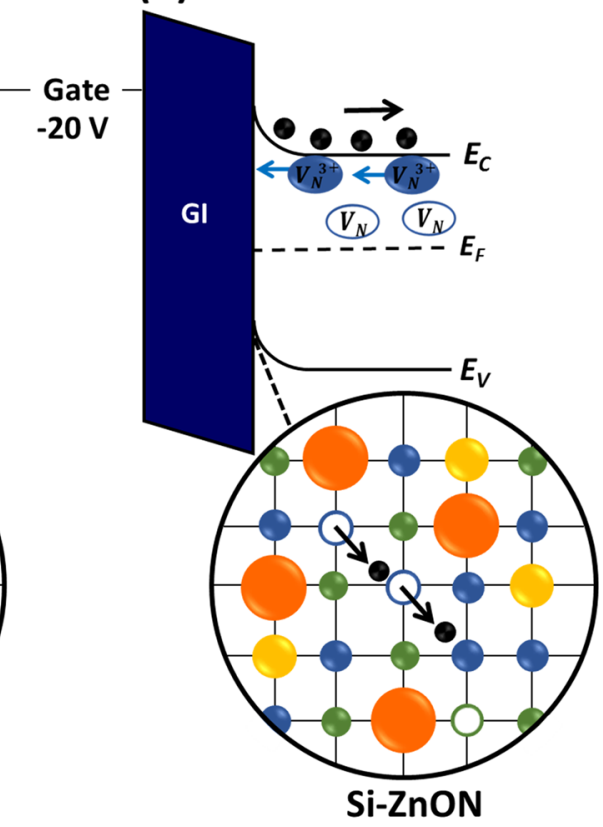

(d) NBIS

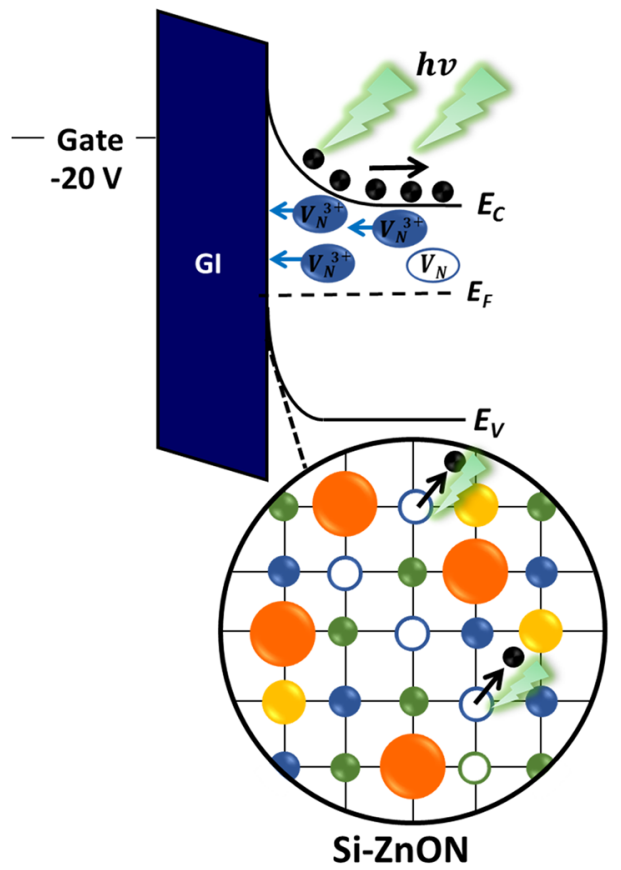

Figure 8. Schematic degradation mechanism of (a) ZnON TFT, and (b) Si 3W-ZnON TFT under NBS; (c) ZnON TFT, and (d) Si 3W-ZnON TFT under NBIS.

examined by XAS through the total electron yield mode at the $10 \mathrm{D}$ beamline of the Pohang accelerator laboratory in Korea. The electronic structures, regarding changes in the absorption coefficient and band alignment, were investigated by SE and XPS. The SE measurements were performed using a rotating-analyzer system with auto retarder.

Theoretical calculations. The Vienna Ab-initio Simulation Package (VASP) was performed for the first-principles calculations employing a plane wave basis set with a kinetic energy cutoff of $400 \mathrm{eV}$, within the projector augmented wave (PAW) pseudopotentials ${ }^{42,43}$. Melt-and Quench Molecular Dynamics (MD) simulations were used to make amorphous $\mathrm{ZnON}$ structures based on the elemental ratio of ZnON from XPS data ${ }^{24}$. Density Functional Theory (DFT) simulations were carried out to calculate the formation energies of nitrogen vacancies $\left(\mathrm{V}_{\mathrm{N}}\right)$ in amorphous $\mathrm{ZnON}$ structure. All calculations used the generalized gradient approximation 
(GGA) method $^{44}$, and the Brillouin zone was sampled with $1 \times 1 \times 1$ (MD) and $2 \times 2 \times 2$ (DFT) k-points mesh. The HSE06 hybrid-functional with $20 \%$ of the HF exchange energy was modified, in order to fit the experimental bandgap of the $\mathrm{ZnON}$ and Si-doped $\mathrm{ZnON}$ structures.

Received: 19 February 2019; Accepted: 26 December 2019;

Published online: 20 January 2020

\section{References}

1. Park, J.-S., Kim, H. \& Kim, I.-D. Overview of electroceramic materials for oxide semiconductor thin film transistors. J. Electroceram. 32, 117-140 (2014).

2. Ye, Y., Lim, R. \& White, J. M. High mobility amorphous zinc oxynitride semiconductor material for thin film transistors. J. Appl. Phys. 106, 074512 (2009).

3. Kim, H.-S. et al. Anion control as a strategy to achieve high-mobility and high-stability oxide thin-film transistors. Sci. Rep. 3, 1459 (2013).

4. Lee, E. et al. Nanocrystalline $\mathrm{ZnON}$; high mobility and low band gap semiconductor material for high performance switch transistor and image sensor application. Sci. Rep. 4, 4948 (2015).

5. Kim, D.-H., Jeong, H.-S., Jeong, C.-Y., Song, S.-H. \& Kwon, H.-I. Effects of oxygen flow rate on the electrical stability of zinc oxynitride thin-film transistors. Jpn. J. Appl. Phys. 56, 020301 (2017).

6. Park, J. et al. A study on the electron transport properties of $\mathrm{ZnON}$ semiconductors with respect to the relative anion content. Sci. Rep. 6, 24787 (2016).

7. Park, J. et al. The effects of active layer thickness and annealing conditions on the electrical performance of $\mathrm{ZnON}$ thin-film transistors. J. Alloys Compd. 688, 666-671 (2016).

8. Jeong, H., Jeong, H.-S., Kim, D.-H., Jeong, C.-Y. \& Kwon, H.-I. Effects of post-deposition thermal annealing temperature on electrical properties of ZnON thin-film transistors. IEEE Electron Device Lett. 37, 747-750 (2016).

9. Ok, K.-C., Jeong, H.-J., Kim, H.-S. \& Park, J.-S. Highly stable ZnON thin-film transistors with high field-effect mobility exceeding $50 \mathrm{~cm}^{2} / \mathrm{Vs}$. IEEE Electron Device Lett. 36, 38-40 (2015).

10. Nomura, K. et al. Room-temperature fabrication of transparent flexible thin-film transistors using amorphous oxide semiconductors. Nature 432, 488-492 (2004).

11. Park, J. S., Maeng, W.-J., Kim, H.-S. \& Park, J.-S. Review of recent developments in amorphous oxide semiconductor thin-film transistor devices. Thin Solid Films 520, 1679-1693 (2012).

12. Long, R., Dai, Y., Yu, L., Huang, B. \& Han, S. Atomic geometry and electronic structure of defects in $\mathrm{Zn}_{3} \mathrm{~N}_{2}$. Thin Solid Films 516, 1297-1301 (2008).

13. Lee, S., Nathan, A., Ye, Y., Guo, Y. \& Robertson, J. Localized tail states and electron mobility in amorphous ZnON thin film transistors. Sci. Rep. 5, 13467 (2015).

14. Kim, H.-S. et al. Defect control in zinc oxynitride semiconductor for high-performance and high-stability thin-film transistors. Solid State Phenom. 205, 446-450 (2013).

15. Choi, J. Y. et al. Engineering of band gap states of amorphous SiZnSnO semiconductor as a function of Si doping concentration. Sci. Rep. 6, 36504 (2016).

16. Chong, E., Kang, I., Park, C. H. \& Lee, S. Y. First-principle study of amorphous SiZnSnO thin-film transistor with excellent stability. Thin Solid Films 534, 609-613 (2013).

17. Chong, E., Kim, S. H. \& Lee, S. Y. Role of silicon in silicon-indium-zinc-oxide thin-film transistor. Appl. Phys. Lett. 97,252112 (2010).

18. Dean, J. A. Lange’s handbook of chemistry, McGRAW-HILL, INC., (1968).

19. Wang, Y. F. et al. Improvement of thermal stability of $\mathrm{p}$-type $\mathrm{ZnO}:(\mathrm{Al}, \mathrm{N})$ fabricated by oxidizing $\mathrm{Zn}_{3} \mathrm{~N}_{2}: \mathrm{Al}$ thin films. Phys. Status Solidi C 13, 585-589 (2016).

20. Park, H.-W., Kim, B. K., Park, J.-S. \& Chung, K.-B. Device performance and bias instability of Ta doped InZnO thin film transistor as a function of process pressure. Appl. Phys. Lett. 102, 102102 (2013).

21. Sevik, C. \& Bulutay, C. Theoretical study of the insulating oxides and nitrides: $\mathrm{SiO}_{2}, \mathrm{GeO}_{2}, \mathrm{Al}_{2} \mathrm{O}_{3}, \mathrm{Si}_{3} \mathrm{~N}_{4}$, and $\mathrm{Ge}_{3} \mathrm{~N}_{4}$. J.Mater.Sci. 42, 6555-6565 (2007).

22. Libsch, F. R. \& Kanicki, J. Bias-stress-induced stretched-exponential time dependence of charge injection and trapping in amorphous thin-film transistors. Appl. Phys. Lett. 62, 1286 (1993).

23. Berkel, C. V. \& Powell, M. J. Resolution of amorphous silicon thin film transistor instability mechanisms using ambipolar transistors. Appl. Phys. Lett. 51, 1094 (1987).

24. Park, J., Jeong, H.-J., Lee, H.-M., Nahm, H.-H. \& Park, J.-S. The resonant interaction between anions or vacancies in ZnON semiconductors and their effects on thin film device properties. Sci. Rep. 7, 2111 (2017).

25. Kim, H.-D. et al. Effects of fluorine doping on the electrical performance of $\mathrm{ZnON}$ thin-film transistors. ACS Appl. Mater. Interfaces. 9, 24688-24695 (2017).

26. Li, S., Wang, M., Zhang, D., Wang, H. \& Shan, Q. A unified degradation model of a-InGaZnO TFTs under negative gate bias with or without an illumination. IEEE J Electron Devi. 7, 1063-1071 (2019).

27. Park, H.-W., Kwon, S., Song, A., Choi, D. \& Chung, K.-B. Dynamics of bias instability in the tungsten-indium-zinc oxide thin film transistor. J. Mater. Chem. C 7, 1006-1013 (2019).

28. Ok, K.-C., Jeong, H.-J., Lee, H.-M., Park, J. \& Park, J.-S. Comparative studies on the physical and electronic properties of reactively sputtered $\mathrm{ZnO}$ and $\mathrm{ZnON}$ semiconductors. Ceram. Int. 41, 13281-13284 (2015).

29. Jeon, J.-H., Kim, J. \& Ryu, M.-K. Instability of an amorphous indium gallium zinc oxide TFT under bias and light illumination. J. Korean Phys.Soc. 58, 158 (2001).

30. Cheng, H.-Y., Chen, Y.-C., Chung, R.-J. \& Chin, T.-S. Highly electrical resistive SiTiN $_{\mathrm{x}}$ heating layers and diffusion barriers for PCRAM. Semicond. Sci. Technol. 21, 1196 (2006).

31. Yang, J. et al. Plasma enhanced chemical vapor deposition silicon nitride for a high-performance lithium ion battery anode. Power Sources 269, 520-525 (2014).

32. Song, A. et al. Modulation of the electrical properties in amorphous indium-gallium zinc-oxide semiconductor films using hydrogen incorporation. Appl. Phys. Lett. 111, 243507 (2017).

33. Kim, J. W. et al. Chemical configuration of nitrogen in ultrathin Si oxynitride on Si (100). Physical Review B 66, 035312 (2002).

34. Gao, H., Zhang, X., Zhao, Y. \& Yan, B. Effect of process pressure and temperature on ZnON material properties in reactive sputtering. AIP Adv. 7, 035311 (2017).

35. Kim, H. et al. Impact of bias stability for crystalline InZnO thin-film transistors. Appl. Phys. Lett. 110, 232104 (2017).

36. Kim, B. K., Park, J.-S., Kim, D. H. \& Chung, K.-B. Semiconducting properties of amorphous GaZnSnO thin film based on combinatorial electronic structures. Appl. Phys. Lett. 104, 182106 (2014).

37. Ahn, B. D. et al. Origin of electrical improvement of amorphous TaInZnO TFT by oxygen thermo-pressure-induced process. J. Phys. D: Appl. Phys. 47, 105104 (2014) 
38. Park, H.-W. et al. Modification of the electronic structure and the electrical properties of $\mathrm{ZnO}$ thin films by nickel- ion irradiation at room temperature. J. Korean Phys. Soc. 68, 190-194 (2016).

39. Park, H.-W., Song, A., Kwon, S., Ahn, B. D. \& Chung, K.-B. Improvement of device performance and instability of tungsten-doped InZnO thin-film transistor with respect to doping concentration. Appl.Phys.Express. 9, 111101 (2016).

40. Park, H.-W., Park, J.-S., Lee, J. H. \& Chung, K.-B. Thermal evolution of band edge states in $\mathrm{ZnO}$ film as a function of annealing ambient atmosphere. Electrochem. Solid State Lett. 15, H133-H135 (2012).

41. Janotti, A. \& Van de Walle, C. G. Native defects in ZnO. Phys. Rew. B 76, 165202 (2007).

42. Kresse, G. \& Hafner, J. Ab initio molecular dynamics for liquid metals. Phys. Rev. B 47, 558 (1993).

43. Perdew, J. P., Burke, K. \& Ernzerhof, M. Generalized gradient approximation made simple. Phys. Rev. Lett. 77, 3865 (1996).

44. Blöchl, P. E. Projector augmented-wave method. Phys Rev. B 50, 17953 (1994)

\section{Acknowledgements}

This research was supported by Samsung Display Co. Ltd. and Basic Science Research Program through the National Research Foundation of Korea (NRF) funded by the Ministry of Education (2016R1A6A1A03012877 and NRF-2019R1I1A2A01064153), National Research Foundation of Korea (NRF) Grant funded by the Ministry of Science and ICT for First-Mover Program for Accelerating Disruptive Technology Development (NRF2018M3C1B9088457), and the National Institute of Supercomputing and Network/Korea Institute of Science and Technology Information with supercomputing resources including technical support (Grant No: KSC2017-C2-0043).

\section{Author contributions}

A.S. designed the experimental concept and wrote the main manuscript text. H.-D.K. and H.-W.P. discussed the experimental results and commented on theoretical mechanism. All authors reviewed the manuscript. The project was guided by H.-S.K. and K.-B.C.

\section{Competing interests}

The authors declare no competing interests.

\section{Additional information}

Supplementary information is available for this paper at https://doi.org/10.1038/s41598-020-57642-2.

Correspondence and requests for materials should be addressed to H.-S.K. or K.-B.C.

Reprints and permissions information is available at www.nature.com/reprints.

Publisher's note Springer Nature remains neutral with regard to jurisdictional claims in published maps and institutional affiliations.

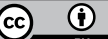

Open Access This article is licensed under a Creative Commons Attribution 4.0 International License, which permits use, sharing, adaptation, distribution and reproduction in any medium or format, as long as you give appropriate credit to the original author(s) and the source, provide a link to the Creative Commons license, and indicate if changes were made. The images or other third party material in this article are included in the article's Creative Commons license, unless indicated otherwise in a credit line to the material. If material is not included in the article's Creative Commons license and your intended use is not permitted by statutory regulation or exceeds the permitted use, you will need to obtain permission directly from the copyright holder. To view a copy of this license, visit http://creativecommons.org/licenses/by/4.0/.

(c) The Author(s) 2020 